\title{
Interlinkage Between Persistent Organic Pollutants and Plastic in the Waste Management System of India: An Overview
}

\author{
Paromita Chakraborty ${ }^{1}$ (D) Sarath Chandra ${ }^{2} \cdot$ Malene Vågen Dimmen $^{3} \cdot$ Rachel Hurley $^{3} \cdot$ Smita Mohanty $^{4}$. \\ Girija K. Bharat ${ }^{5}$ - Eirik Hovland Steindal ${ }^{3,6} \cdot$ Marianne Olsen $^{3} \cdot$ Luca Nizzetto $^{3,7}$
}

Received: 1 October 2021 / Accepted: 10 January 2022 / Published online: 18 February 2022

(c) The Author(s), under exclusive licence to Springer Science+Business Media, LLC, part of Springer Nature 2022

\begin{abstract}
Improper handling of plastic waste and related chemical pollution has garnered much attention in recent years owing to the associated detrimental impacts on human health and the environment. This article reports an overview of the main interlinkages between persistent organic pollutants (POPs) and plastic in the waste management system of India. Both plastics and POPs share certain common traits such as persistence, resistance to biological degradation, and the ability to get transported over long distances. Throughout the processes of production, consumption, and disposal, plastics interact with and accumulate POPs through several mechanisms and end up co-existing in the environment. Plastic waste can undergo long-range transport through rivers and the oceans, break down into microplastics and get transported through the air, or remain locked in waste dump yards and landfills. Over time, environmental processes lead to the leaching and release of accumulated POPs from these plastic wastes. Plastic recycling in the Indian informal sector including smelting, scrubbing, and shredding of plastic waste, is also a potential major POPs source that demands further investigation. The presence of POPs in plastic waste and their fate in the plastic recycling process have not yet been elucidated. By enhancing our understanding of these processes, this paper may aid policy decisions to combat the release of POPs from different waste types and processes in India.
\end{abstract}

Paromita Chakraborty

paromitc@srmist.edu.in

1 Environmental Science and Technology Laboratory, Department of Chemical Engineering, SRM Institute of Science and Technology, Kancheepuram district, Chennai, Tamil Nadu 603203, India

2 Department of Civil Engineering, SRM Institute of Science and Technology, Kancheepuram district, Chennai, Tamil Nadu 603203, India

3 Norwegian Institute for Water Research, Økernveien 94, 0579 Oslo, Norway

4 Central Institute of Petrochemicals Engineering Technology, CIPET, Bhubaneswar, Odisha, India

5 Mu Gamma Consultants Pvt. Ltd, Gurgaon, India

6 Department of International Environment and Development Studies, Norwegian University of Life Sciences, Ås, Norway

7 Research Centre for Toxic Compounds in the Environment (RECETOX), Kamenice 753/5, 62500 Brno, Czech Republic 


\section{Graphical Abstract}

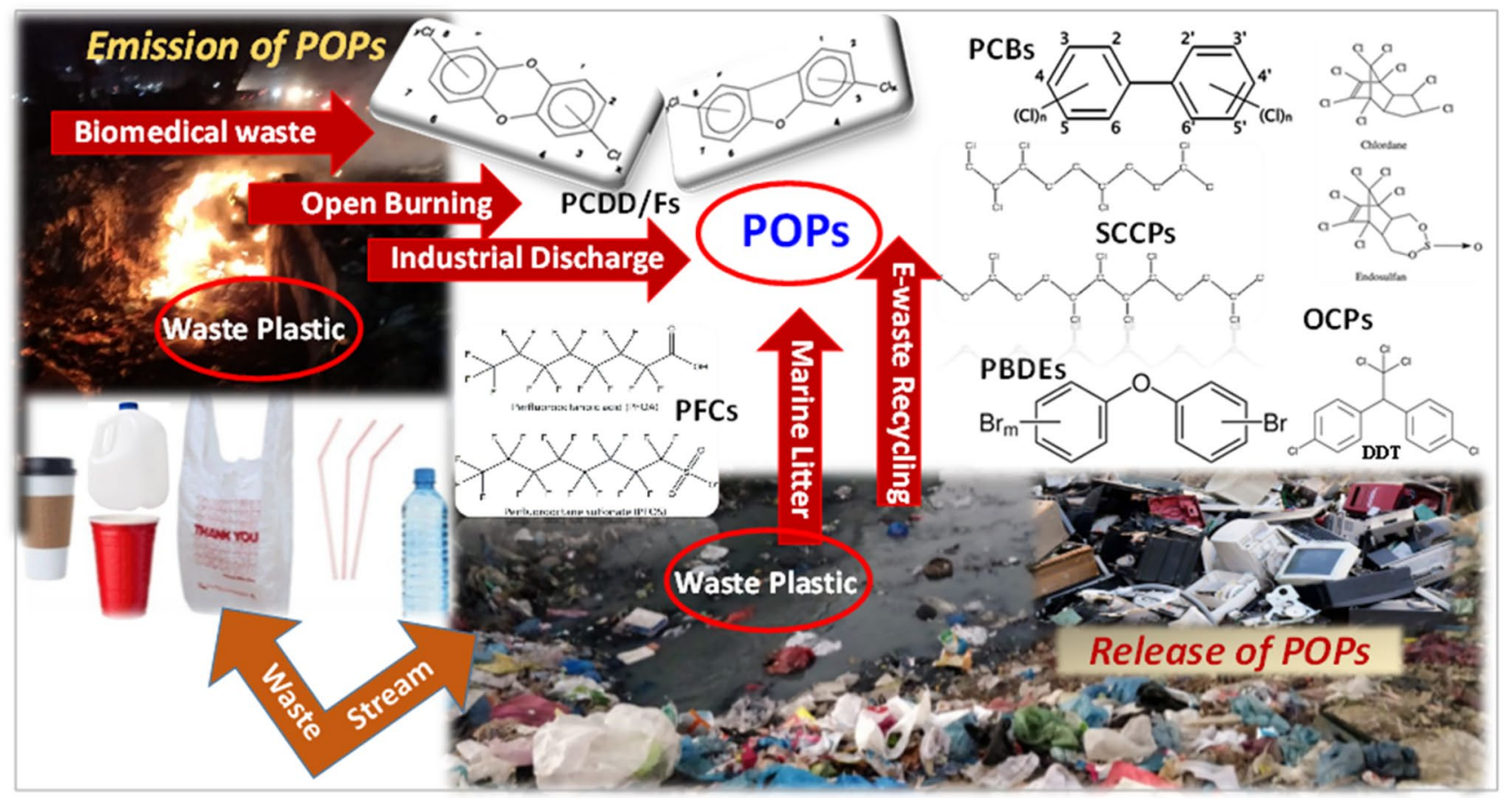

Keywords Waste plastic $\cdot$ Recycling $\cdot$ Processes $\cdot$ Persistent organic pollutants $\cdot$ India

Due to their low degradation rate, plastics accumulate in terrestrial, aquatic, and marine ecosystems, with the latter being considered the ultimate recipient. This includes plastic present across a wide spectrum of sizes: from macroplastic litter to small micro- and nano-plastics. Around 0.8-2.7 million tonnes of plastic waste are released to the oceans each year (Meijer et al. 2021). The sources of plastic pollution are predominantly associated with land-based anthropogenic activities. Such undertakings include: losses during production and transport, public littering, inadequate industrial disposal of end-of-life products, improper municipal waste management (e.g., open dumping grounds and ineffective wastewater treatment plants), runoff or aerial dispersion from soils treated with sewage sludge (frequently used as a soil fertilizer) or agricultural plastics, and losses during product wear (e.g., clothes releasing synthetic fibers). Studies report that plastic pollution is globally pervasive, even reaching remote regions (Allen et al. 2019). Adding to the scale and impact of plastic pollution, significant concern has been raised in recent years about how plastics interact or relate to chemicals, including substances known to be hazardous to human health and the environment. One such group of chemicals (which since the 1990s have received extensive attention for its hazard potential) are the persistent organic pollutants (POPs), regulated under the Stockholm Convention since 2004.

Plastic being light weight, durable and cost effective, can be tailor-made to fit various needs. During production, appropriate chemical addition can impart the desired characteristic to the plastic matrix by physical or chemical interactions with the polymer chain. Plastics are used in a myriad of ways and inevitably cross paths with POPs during the course of their lifecycle. Some of the chemical additives added to plastics during production are POPs themselves e.g., brominated flame retardants like polybrominated diphenyl ethers (PBDEs), polyfluorinated alkyl substances (PFAS/ PFOS) etc. contributing to unintentional POPs release. During their usage, plastics can also come in contact with POPs and can adsorb them onto their surface, acting as a vector (Koelmans et al. 2016; Mato et al. 2001; Teuten et al. 2009). The smaller the plastic particle, the larger the surface area, thereby leading to increased potential for accumulation of toxins (Andrady 2011). Upon end of life, such plastics are either recycled or disposed of. POPs release during recycling activities is also a likely scenario owing to the dedusting, washing, and heating processes that are part of the recycling process pipeline (Chen et al. 2020; Maddela et al. 2020). In the case of disposal, plastics can emit the imbibed POPs either during incineration/combustion activities or 
via leaching. In India and other developing countries, open burning of municipal solid waste and plastic waste recycling in the informal sector (including electronic and electrical waste) are known to be primary release pathways for plasticassociated POPs such as flame retardants, dioxins and furans (Chakraborty et al. 2018, 2017).

Some of the additives used to modify the properties of plastics are biologically active, potentially affecting the development and reproduction of living organisms (Meeker et al. 2009; Oehlmann et al. 2009). Despite documented persistence in the environment, large primary plastic debris also break down into smaller fragments known as microplastics and nanoplastics (Thompson et al. 2004). Much of the concern around these small plastic particles is associated with their potential role as vectors of POPs into terrestrial and marine ecosystems (Cole et al. 2011; Ivar do Sul and Costa 2014). Studies have documented ingestion of small plastic particles by a range of organisms (e.g. Thompson et al. 2004; Boerger et al. 2010), including several species that represents critical trophic links in many oceanic ecosystems (Davison and Asch 2011). Consequently, there is concern that POPs may transfer to organisms following ingestion, potentially leading to negative effects (Koelmans et al. 2016).

The present paper provides an overview of potential important interlinkages between POPs and plastics from different waste streams in India. Drawing on the analysis, relevant control measures are elucidated and promoted.

\section{Methodology}

To map and assess the interlinkages between POPs and plastic in the waste stream in India a comprehensive literature review was carried out. The scientific literature was screened for research articles focusing on the combination of POPs and various aspects of the waste stream processes associated with plastics. The following search terms were used: 'POPs name/acronym', 'India', 'air', 'water', 'soil', 'plastic', 'waste'. Search was on the main name of 30 POPs currently listed under the Stockholm Convention. Seven categories of POPs namely, polychlorinated biphenyls (PCBs), polybrominated diphenyl ethers (PBDEs), organochlorine pesticides (OCPs), polyfluorinated alkyl substances, perfluoro octane sulfonic acid (PFAS/PFOS), polychlorinated dibenzo dioxins/furans (PCDD/Fs), short chain chlorinated paraffins (SCCPs) were mostly reported in scientific articles from India. Wider terms such as 'chemicals', 'substances' and 'Stockholm Convention' were avoided to limit the scope of the paper, in confidence of capturing a representative part of the literature without this segment. Wider terms such as 'chemicals', 'substances' and 'Stockholm Convention' were avoided to limit the scope of the paper, in confidence of capturing a representative part of the literature without these additions. Widely used search engines were used to identify relevant publications: Google Scholar (number of papers, $n=683)$, Pubmed $(n=77)$, Springer $(n=256)$, and Science Direct $(\mathrm{n}=476)$. The review and subsequent assessment were supplemented with secondary sources, including guidance documents and policy documents developed under the Basel Convention on the Control of Transboundary Movements of Hazardous Wastes and their Disposal and the Stockholm Convention. The Basel and Stockholm conventions have established technical guidelines on how to handle POPs contaminated wastes. Member countries contribute to the conventions by voluntarily reporting POPs inventories, technology sharing and strategies for management of POPs waste (Basel Convention 1992; Stockholm Convention 2001). The literature review had three main goals to fulfill. First, to detail the background information regarding plastic generation, use and waste in India and elaborate on India's waste streams. Second, to elucidate about POPs and their relevance in both the global and Indian context by providing insights about their prevalence in various environmental matrices. Finally, to establish a clear link or association between plastics and POPs through various phases of the plastic lifecycle. A total of 1492 results were returned upon searching for the above-mentioned keywords using combination operators OR/AND. Criteria for inclusion of an article comprised of published studies containing any of the seven most frequently reported POPs and studies detailing plastic waste generation and management, emissions, or release of POPs from waste streams. Studies focusing on India were prioritised where available. Of the 1492 results, 70 articles were selected after careful review based on their relevance to elucidating plastic-POPs interlinkages. References were collected and stored using Mendeley open-source reference manager software.

\section{Discussion}

India generates around 6.5 to 8.5 million tons of recyclable plastic waste every year (Nandy et al. 2015). Over 60\% of the plastics consumed have a service life of less than 3 years and contribute to waste generation from households, industries and other establishments (Mutha et al. 2006). Plastic waste in India comes under the purview of Plastic Waste Management (Amendment) Rules (2021), issued by the Ministry of Environment Forest and Climate Change. While the rules recommend source level segregation of plastic waste from the solid waste stream, the national-level source-segregation figure stands at only $48 \%$. Just $37 \%$ of the total generated waste is considered fit for recycling (Shukla et al. 2021). Polypropylene plastic (PP) is the most consumed polymer type in Indian cities $(25 \%)$ closely followed by polyvinyl chloride (PVC) (20\%) (Singh et al. 2019). While the 
collection efficiency of these two plastics types was determined to be over $80 \%$ in 2014 , only $28.4 \%$ was effectively treated (Bhattacharya et al. 2018). In a study of plastic waste in 60 Indian cities, conducted by the Indian government in 2015 , it was estimated that $7 \%$ of the waste stream was plastic. With the sharp increase in the use of plastic products in India, in a business-as-usual scenario, India is set to become the largest generator of mismanaged plastic waste by 2035 (Lebreton and Andrady 2019).

While the Indian government has enacted the Regulation of Persistent Organic Pollutants Rules, the legislation represents a barebones version and only includes seven of the thirty POPs that the Stockholm Convention has listed. The existing Hazardous and Other Wastes Management and Transboundary Movement rule discussion is limited to waste treatment and disposal facilities. After a ban on single-use plastics by 2022 was announced, an extensive public awareness campaign was initiated in 2021, and new rules on extended producer responsibility (EPR) have just recently been introduced. These selected developments reflect the focus and ambitions on plastic pollution in India, and strongly points in the direction of future expansion of the plastic recycling market. While discussing plastic recycling, different POPs are associated with different parts of the plastic waste's lifecycle. We have tabulated the plastic waste types that can be expected from the major waste streams in India and their associated POPs (Table 1; Fig. 1).
In India, plastic waste is not always handled properly and a significant component ends up in dump yards (Chakraborty et al. 2019). There is limited data on the management and treatment of plastic waste in India; however, a few government campaigns have been carried out to assess the components and plastic types of municipal waste in selected cities. As part of these campaigns, it has been estimated that 15,342 tons of plastic waste is generated daily. Yet, this is only representing the collected fraction of municipal solid waste, where, in some cities, this has been reported to be below 50\% (Kumari et al. 2019). Furthermore, there are no reliable estimates of how much plastic waste is being captured and recycled at a national level. Plastics in the dump yard waste stream originate primarily from households, institutions, and other establishments and are governed by the Solid Waste Management Rules (2021). They may interact with and accumulate POPs at any stage of production, usage, or disposal. Despite open burning of plastic waste being banned in India, burning of unsegregated garbage containing plastics is frequently practiced and is highly prevalent throughout the country (Velis and Cook 2021). Weathered plastic material in the dumpsites may also leach into the soil and groundwater systems, potentially spreading contamination to other connected ecosystems. Unmanaged landfills are known to be a major source of chemical groundwater contamination (Staines et al. 2004; Weber et al. 2011). Plastics from dump yard wastes are also highly heterogeneous and exhibit differences in composition based on a variety of factors. POPs

Table 1 List of plastic types, uses, associated POPs and major waste contributor

\begin{tabular}{|c|c|c|c|}
\hline Major waste contributor & Plastic type & Uses/applications & Possible POPs \\
\hline $\begin{array}{l}\text { Dumpyard waste } \\
\text { E-waste } \\
\text { Biomedical waste } \\
\text { Marine litter } \\
\text { Industrial waste }\end{array}$ & $\begin{array}{l}\text { High density polyethylene (HDPE) } \\
\text { Poly vinyl chloride (PVC) } \\
\text { Crosslinked polyethylene (XLPE) }\end{array}$ & Electrical insulation, bottles, toys & $\begin{array}{l}\text { PBDEs, PFAS/PFOS, OCPs, PCDD/Fs, } \\
\text { SCCPs, PCBs }\end{array}$ \\
\hline $\begin{array}{l}\text { Dumpyard waste } \\
\text { Biomedical waste } \\
\text { Marine litter } \\
\text { Industrial waste }\end{array}$ & Low density polyethylene (LDPE) & Film wrap, plastic bags & OCPs, PCDD/Fs, SCCPs \\
\hline $\begin{array}{l}\text { Dumpyard waste } \\
\text { E-waste } \\
\text { Biomedical waste } \\
\text { Industrial waste }\end{array}$ & Poly vinyl chloride (PVC) & Pipes, siding, flooring & PDBEs, PFAS/PFOS, PCDD/Fs, PCBs \\
\hline $\begin{array}{l}\text { E-waste } \\
\text { Marine litter } \\
\text { Industrial waste }\end{array}$ & $\begin{array}{l}\text { Polystyrene (PS) } \\
\text { Expanded polystyrene (EPS) } \\
\text { High impact polystyrene (HIPS) }\end{array}$ & $\begin{array}{l}\text { Toys, cabinets, packaging } \\
\text { (Foamed), coatings for wirings, } \\
\text { cables, construction }\end{array}$ & PBDEs, PFAS/PFOS, PCDD/Fs \\
\hline $\begin{array}{l}\text { Biomedical waste } \\
\text { Marine litter }\end{array}$ & Polyethylene Terephthalate (PET) & Packaging, bottles, clothing & PBDEs, PCDD/Fs, PCBs \\
\hline $\begin{array}{l}\text { Biomedical waste } \\
\text { Marine litter }\end{array}$ & $\begin{array}{l}\text { Polypropylene (PP) } \\
\text { Poly vinyl chloride (PVC) }\end{array}$ & Containers, carpet, upholstery & OCPs, PCDD/Fs, SCCPs \\
\hline $\begin{array}{l}\text { E-waste } \\
\text { Industrial waste }\end{array}$ & $\begin{array}{l}\text { Acrylonitrile butadiene styrene } \\
\text { (ABS); Polycarbonate (PC) its } \\
\text { blends } \\
\text { Other plastics etc }\end{array}$ & $\begin{array}{l}\text { Instrument panels, dashboards, } \\
\text { electrical appliances, mobile } \\
\text { phone casings }\end{array}$ & PBDEs, PFAS/PFOS, PCDD/Fs \\
\hline
\end{tabular}




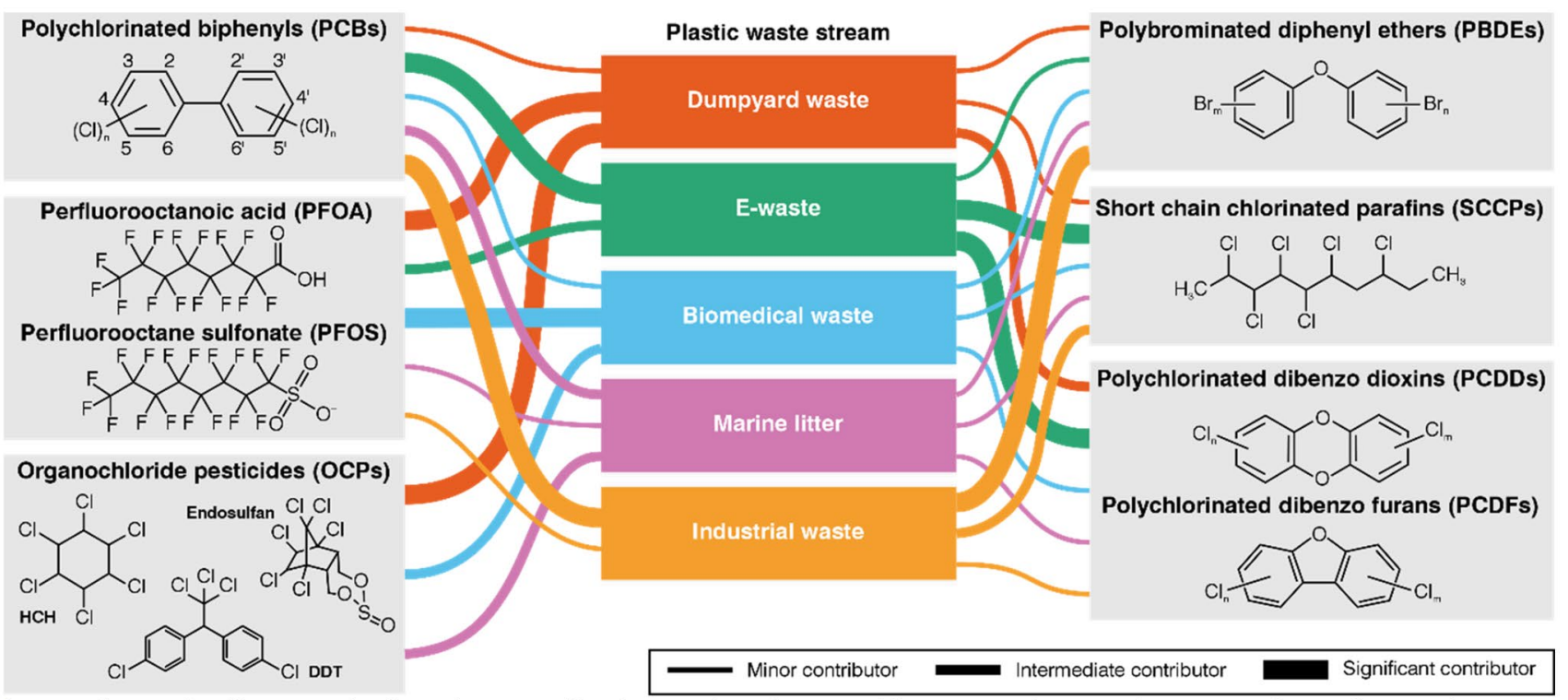

Fig. 1 Schematic diagram depicts the contribution and pathway of legacy and emerging POPs from five major waste streams in India

from dump yard plastics are likely to be varied in nature given the vast geographical area from which the waste is typically sourced. There is a high likelihood of the plastic adsorbing POPs or they may already contain POPs in the form of residues, coatings, or splashes before input into the dump. Once the waste is present in the dump site, it may act as a source for chemical leaching in the dumpsite.

Waste burning is a cheap and effective means of volume reduction and is used both in dump yards and neighbourhoods in India to reduce the height of a waste pile (Wiedinmyer et al. 2014). Over $41 \%$ of the world's waste is treated via uncontrolled burning (Wiedinmyer et al. 2014). For India in the year 2020, of the 192 teragrams of generated waste, open burning of waste was estimated to account for 74 teragrams (Chaudhary et al. 2021). This process is a major source of POPs emission, in both gaseous and sometimes particulate form. Open burning of plastic waste is subsumed as a part of the open burning of solid waste. Although such practices are also taking place in developed countries, it is far more frequent in developing countries as their waste segregation policies, recycling and waste processing systems are incapable of handling such high waste volumes. Sometimes, the combustion is spontaneous and unintended, even uncontrolled, e.g. when a dumpsite catches fire. Plastics in the solid waste stream combine with oxygen in the atmosphere to form hazardous halogenated dioxins and furans when burned. Plastics which contain chlorine (e.g. PVC) give rise to one of the most toxic compounds: PCDD/Fs. In India, tonnes of plastics are burned every day in many of the states and cities. Incomplete or complete combustion of polymeric materials, resulted in release of $\mathrm{PCDD} / \mathrm{Fs}$ and dioxin like-PCBs (dl-PCBs) in Indian cities (Chakraborty et al. 2018; Rajan et al. 2021). Leachate quality and gas quality monitoring are mandated to be carried out in the dump yards of India as per Central Public Health and Environmental Engineering Organisation regulations and Solid Waste Management Rules (2018). While leachate and gas monitoring in dumpyard are mandatory, these do not include POPs. Hence it is not possible to accurately and quantitatively estimate the contribution of this source to the total POP emission inventories. A study monitored POP levels in the dumping site of Kolkata evidenced that the population living around the dumpsite is exposed to relatively high levels of PCBs in human milk (43-890 ng/g) (Someya et al. 2010). Similarly, analysis of fish samples for dioxins revealed extremely high concentrations of dl-PCBs in fish collected from a pond near the dumping site (total monoortho PCBs 220-1300 ng/g) compared to reference site (total mono-ortho PCBs 14-17 ng/g) (Someya et al. 2010). Due to the open burning of dumped solid waste, SCCPs in the Indian atmosphere were significantly higher than the ambient air in Japan, South Korea, and Pakistan, where the concentration of SCCPs was comparable (Chaemfa et al. 2014). Elevated levels of PCBs and PBDEs were also found in a dumpsite with frequent open burning activities (Hafeez et al. 2016).

The informal plastic recycling sector in India handles a vast amount of waste every year. Estimates provided by the Government of India suggest that 15,600 tons (58\%) of the 26,000 tons of total plastic waste generated each day are handled and recycled by the informal sector; however, these numbers remain difficult to validate. The handling of plastic waste also incorporates the handling of plastic-associated POPs. As the informal recycling processes do not have the 
facilities necessary for a "closed" recycling process, POPs are released via air and run-off in recycling activities such as smelting, shredding, dedusting, and scrubbing. Informal waste workers have reported that plastic waste containing brominated flame retardants will be mixed with other plastic when the unit price is low, whereas when the market has a demand for slow-burning, combustion resistant material, the POPs containing plastics will be treated separately (Chakraborty et al. 2016a; Rex et al. 2019). Furthermore, the rejected, non-recyclable component that accumulates at the recycling sites-estimated to be $10 \%$ of the total plastic managed at the site-is bought by local brick-makers or in cement kiln and used as fuel (Nizzetto and Sinha 2020). Since the temperature at these premises is rather high, this activity may generate significant dioxin and furan emissions. Consequently, the informal sector, and its associated activities, represents a potential major POPs source. Despite this, there is a severe lack of studies investigating how, where, which, and how much POPs are released to the environment from the Indian informal plastic waste recycling/reuse sector. There are studies addressing this issue in other Asian countries by detailing/evaluating material flows of various plastic waste recycling activities and information about their associated POPs like PBDEs, PCDD/Fs such as their production and usage (Shinkuma and Huong 2009; Tang et al. 2014; Chen et al. 2020; Maddela et al. 2020). Whereas in India, such information (e.g. Kumari et al. 2014) is relatively sparse. Though India is a signatory to the Stockholm Convention and has taken significant measures towards remediating the initial 12 POPs, India needs to focus on effective implementation of the regulation of the brominated flame retardants (BFRs) under the Stockholm Convention (UN, 2020; Stockholm Convention, 2022). They have passed regulations to limit the import, export, and new-use of penta/octa-BDEs; however, there is a notable absence of regulations regarding the recycling of PBDE-treated plastics (Toxics Link 2018). Atmospheric emissions of PBDEs related to these formulations were evident in Indian cities (Chakraborty et al. 2017).

Electronic waste includes any unused or discarded electrical or electronic item intended for resource recovery, recycling or disposal (Makkar Panwar et al. 2018). Given the huge demand for better and more up to date technology, electronic goods production has surged in recent years. A recent report estimates that e-waste generation in 2017 has reached 44.7 million tonnes each year (WEF 2019). Between 25 and 35\% of e-waste is plastic (Rex et al. 2019). In India, the informal sector recycles about 95\% of e-waste (Chakraborty et al. 2016b) this includes a substantial contribution from internationally traded e-waste from developing countries. Urban slums and suburbs of India's major metropolitan cities are the locations where informal recycling take place. The recycling process undertaken is extremely rudimentary. Improper handling likely causes the release of harmful POPs that are imbibed within e-waste components (Chakraborty et al. 2016a) Low temperature combustion of e-waste components, acid leaching for precious metal recovery and improper waste management are the primary contributors to POPs release from e-waste plastics by the informal e-waste recycling sector (Chakraborty et al. 2018). Very high PCB contamination in the surface soil of Indian cities have been observed in the informal e-waste recycling workshops engaged in precious metal recovery $(88 \%)$, followed by grinding or shredding workshops (4\%), dismantling sites (4\%) and open dumpsites (4\%) (Chakraborty et al. 2018). Plastic processing, open burning in dumpsites and informal e-waste recycling at specific locations within each metropolitan city of India are suspected to have collectively impacted the atmospheric emission of PBDEs at the local or even regional scales (Chakraborty et al. 2017). A significant correlation between a potentially hazardous plasticizer DEHP and the highly toxic PCB congener (PCB-126) was found at the same e-waste shredding and recovery sites where extensive burning of plastic or PVC materials were prevalent, reflecting an emergency source of POPs by the informal sector (Chakraborty et al. 2019).

Industrial waste is a nebulous term that includes waste generated from offices and commercial buildings, as well as large manufacturing and processing plants. Industries represent some of the largest users of packaging, insulation, and plastic products augmented with various additives, many of them POPs or POPs precursors, to safeguard and improve durability (Breivik et al. 2004; Sharma et al. 2014). As a consequence, plastic waste from manufacturing and industrial activities is likely to be a major source of POPs. Various industrial wastes can sometimes concurrently release POPs in a more effective manner than any standalone waste component (Sakai et al. 1998). The most obvious industrial waste stream that contains POPs is the wastes from the chemical production of established POPs like pesticides, flame retardants, surfactant chemicals (Hong et al. 2010; Chakraborty et al. 2010, 2015; Shan et al. 2014). These industrial waste plastics can release POPs into the environment either during their production or processing via stack and effluent emissions or via leaching and weathering after being dumped or littered. Emission of several POPs from the industrial and allied sectors is an important source for atmospheric plasticizers and POPs such as PCBs, PCDD/Fs etc. in India (Chakraborty et al. 2021). Disposal of industrial waste by co-processing can also give rise to unintentional production of POPs (uPOPs), unless it is combusted at adequately high temperature and the waste products are handled properly (Khumsaeng et al. 2013). While there are some established guidelines for industrial waste streams that are related to primary production of POPs and their related goods, the 
problem remains multi-pronged and must be tackled from several angles, considering adequate economic, technological and policy measures.

Plastic waste from hospitals and healthcare facilities is deemed to be part of "biomedical waste" as per the "Biomedical Waste Management (Amendment) Rules, 2018". They cannot be mixed with regular garbage and the plastics are not permitted to be recycled without complete disinfection. Outbreak of COVID-19 pandemic has resulted in further addition of plastic waste to the biomedical waste stream, particularly from personal protective equipment. One of the methods for handling plastic biomedical waste is incineration. As per the Bio-Medical Waste Management (Amendment) Rules, 2018, all healthcare establishments were required to phase out chlorinated plastic bags (excluding blood bags) and gloves by March 2019. Despite this regulatory requirement, there may be other chlorinated plastic use in hospitals leading to the formation of PCDD/Fs during incineration (Mininni et al. 2007). PCB congeners can also be co-generated with $\mathrm{PCDD} / \mathrm{Fs}$ in incineration plants as observed in India (Chakraborty et al. 2016a, b)]. Many incinerators are inefficient in controlling dioxin emissions because of the poor performance of combustion chambers or air pollution control devices, discontinuous operation, or irregular waste feeding (Thacker et al. 2013). Recently, the quantity of biomedical waste plastics has surged due to the COVID-19 pandemic. The emphasis on safety and health has brought back the concept of "single use" plastics such as disposable face masks, gloves, PPEs, and wipes (Benson et al. 2021). India generated $10 \%$ higher quantities of biomedical waste during the pandemic period leading to increased biomedical plastics (Ramteke and Sahu 2020). Without proper incineration, biomedical waste processing not only ends up as a part of the improperly dumped waste fraction, but potentially as an unintentional source for POPs.

Rivers act as conduits for inland plastic wastes to reach the oceans. Widespread littering and waste dumping into riverine systems of the world have resulted in high plastic flows and accumulations in inland waterways, representing a potential threat to both riverine and marine ecosystems. Plastic marine litter includes various materials and chemicals, in which plastic macromolecules (polymers) tend to dominate. It comprises of such diverse items as fishing gear, agricultural plastics, bottles, bags, food packaging, taps, lids, straws, cigarette butts, industrial pellets, and cosmetic microbeads. Their fragmentation debris is the result of natural weathering processes such as wind and water abrasion, leaching, photolytic degradation etc. (Gallo et al. 2018). Plastic resin pellets collected in 30 beaches in 17 countries around the world were found to contain different POPs such as HCHs and DDTs (Ogata et al. 2009). These compounds' particulate, liquid, and gaseous emissions co-occur upon crude recycling of e-waste (Sepúlveda et al. 2010). Riverine/ marine litter also gives rise to the generation and spread of microplastics. Microplastics have become prevalent even in the most remote regions of the planet, transported over long ranges by atmospheric and oceanic circulation (e.g. Allen et al. 2019; Free et al. 2014; Imhof et al. 2017; Kelly et al. 2020; Tan et al. 2020; Zhang et al. 2016). As such, riverine/marine plastic litter is a cause for concern, given the potential for the transfer and bioaccumulation of POPs in a range of species upon ingestion, which may incur a range of negative effects (Abdolahpur Monikh et al. 2021; Seltenrich 2015).

In recent years, the focus on sharpening policy, regulation, and management of plastic has gained significant traction both internationally and in India in particular. Channelisation of recyclables to recyclers is urged in the legislation; unfortunately, there is no mandate or incentive for plastic producers to re-procure much of the recycled plastic and close the loop on plastic wastage. India should promote POPs disposal techniques that will destroy them irreversibly to eliminate their persistence and avoid giving rise to toxic byproducts or metabolites. Moreover, measures must be put in place to avoid producers using POPs or POPs contaminated raw materials in manufacturing. Adoption of labelling systems to indicate the number of times a plastic product has been recycled could prove beneficial in tracking recycled and virgin plastic consumption. Provisions can also be made in the regulations to test residual POPs levels in recycled plastics and to set limits on their maximum POPs content. India can implement the scrutiny of flammability standards to reduce the use of hazardous flame retardants which appears to be the increasing purview of European Union regulations (Charbonnet et al. 2020). In collaboration with the international community, and guided by the recommendations developed under the Basel and Stockholm Conventions, best available technologies should be adapted to the Indian situation, preventing serious contamination and impacts on human health and the environment (Basel Convention 1992).

Acknowledgements This work was supported by the India-Norway cooperation project on capacity building for reducing plastic and chemical pollution in India (INOPOL) Project Number IND-19/0005. The Research Council of Norway is also acknowledged for financing Dr Steindal and Dr Nizzetto participation in the research through the project ASAP-Asian Scientific Alliance for Plastic Pollution and Value Network Management (Contract no. 302575).

\section{References}

Abdolahpur Monikh F, Chupani L, Vijver MG, Peijnenburg WJGM (2021) Parental and trophic transfer of nanoscale plastic debris in an assembled aquatic food chain as a function of particle size. 
Environ Pollut 269:116066. https://doi.org/10.1016/j.envpol.2020. 116066

Allen S, Allen D, Phoenix VR et al (2019) (2019) Atmospheric transport and deposition of microplastics in a remote mountain catchment. Nat Geosci 12:339-344. https://doi.org/10.1038/ s41561-019-0335-5

Andrady AL (2011) Microplastics in the marine environment. Mar Pollut Bull 62:1596-1605

Basel Convention (1992) Basel convention on the control of transboundary movements of hazardous wastes and their disposal. https://www.basel.int/Portals/4/Basel\%20Convention/docs/text/ BaselConventionText-e.pdf; Accessed on 09 Feb 2022

Benson NU, Bassey DE, Palanisami T (2021) COVID pollution: impact of COVID-19 pandemic on global plastic waste footprint. Heliyon 7:e06343. https://doi.org/10.1016/j.heliyon.2021.e06343

Bhattacharya S, Chandrasekhar K, Deepthi, et al (2018) Challenges and opportunities: plastic waste management in India. The Energy Research Institute

Breivik K, Alcock R, Li Y-F et al (2004) Primary sources of selected POPs: regional and global scale emission inventories. Environ Pollut 128:3-16. https://doi.org/10.1016/j.envpol.2003.08.031

Chaemfa C, Xu Y, Li J et al (2014) Screening of atmospheric short- and medium-chain chlorinated paraffins in India and Pakistan using polyurethane foam based passive air sampler. Environ Sci Technol 48:4799-4808. https://doi.org/10.1021/es405186m

Chakraborty P, Zhang G, Li J et al (2010) Selected organochlorine pesticides in the atmosphere of major Indian Cities: levels, regional versus local variations, and sources. Environ Sci Technol 44:8038-8043. https://doi.org/10.1021/es102029t

Chakraborty P, Zhang G, Li J et al (2015) Occurrence and sources of selected organochlorine pesticides in the soil of seven major Indian cities: assessment of air-soil exchange. Environ Pollut 204:74-80. https://doi.org/10.1016/j.envpol.2015.04.006

Chakraborty P, Selvaraj S, Nakamura M, et al (2016a) E-Waste and Associated Environmental Contamination in the Asia/Pacific Region (Part 2): A Case Study of Dioxins and Furans in E-Waste Recycling/Dump Sites in India. In: ACS Symposium Series. American Chemical Society, pp 139-154

Chakraborty P, Selvaraj S, Nakamura M, et al (2016b) E-waste and associated environmental contamination in the Asia/Pacific region (part 1): an overview. In: ACS symposium series. American Chemical Society, pp 127-138

Chakraborty P, Zhang G, Cheng H et al (2017) Passive air sampling of polybrominated diphenyl ethers in New Delhi, Kolkata, Mumbai and Chennai: levels, homologous profiling and source apportionment. Environ Pollut 231:1181-1187. https://doi.org/10.1016/j. envpol.2017.08.044

Chakraborty P, Selvaraj S, Nakamura M et al (2018) PCBs and PCDD/ Fs in soil from informal e-waste recycling sites and open dumpsites in India: levels, congener profiles and health risk assessment. Sci Total Environ 621:930-938

Chakraborty P, Sampath S, Mukhopadhyay M et al (2019) Baseline investigation on plasticizers, bisphenol A, polycyclic aromatic hydrocarbons and heavy metals in the surface soil of the informal electronic waste recycling workshops and nearby open dumpsites in Indian metropolitan cities. Environ Pollut 248:1036-1045. https://doi.org/10.1016/j.envpol.2018.11.010

Chakraborty P, Gadhavi H, Prithiviraj B et al (2021) Passive air sampling of PCDD/Fs, PCBs, PAEs, DEHA, and PAHs from informal electronic waste recycling and allied sectors in Indian megacities. Environ Sci Technol 55:9469-9478. https://doi.org/10.1021/acs. est. $1 \mathrm{c} 01460$

Charbonnet JA, Weber R, Blum A (2020) Flammability standards for furniture, building insulation and electronics: benefit and risk. Emerg Contamin 6:432-441. https://doi.org/10.1016/j.emcon. 2020.05.002
Chaudhary P, Garg S, George T et al (2021) Underreporting and open burning: the two largest challenges for sustainable waste management in India. Resour Conserv Recycl 175:105865. https://doi. org/10.1016/j.resconrec.2021.105865

Chen Y, Li J, Tan Q (2020) Trends of production, consumption and environmental emissions of decabromodiphenyl ether in mainland China. Environ Pollut 260:114022. https://doi.org/10. 1016/j.envpol.2020.114022

Cole M, Lindeque P, Halsband C, Galloway TS (2011) Microplastics as contaminants in the marine environment: a review. Mar Pollut Bull 62:2588-2597. https://doi.org/10.1016/j.marpolbul. 2011.09.025

Davison P, Asch R (2011) Plastic ingestion by mesopelagic fishes in the North Pacific subtropical gyre. Mar Ecol Prog Ser 432:173180. https://doi.org/10.3354/meps09142

Free CM, Jensen OP, Mason SA et al (2014) High-levels of microplastic pollution in a large, remote, mountain lake. Mar Pollut Bull 85:156-163. https://doi.org/10.1016/j.marpolbul.2014.06. 001

Gallo F, Fossi C, Weber R et al (2018) Marine litter plastics and microplastics and their toxic chemicals components: the need for urgent preventive measures. Environ Sci Eur 30:1-14

Hafeez S, Mahmood A, Syed JH et al (2016) Waste dumping sites as a potential source of POPs and associated health risks in perspective of current waste management practices in Lahore city, Pakistan. Sci Total Environ 562:953-961. https://doi.org/ 10.1016/j.scitotenv.2016.01.120

Hong SH, Kannan N, Jin Y et al (2010) Temporal trend, spatial distribution, and terrestrial sources of PBDEs and PCBs in Masan Bay, Korea. Mar Pollut Bull 60:1836-1841. https://doi.org/10. 1016/j.marpolbul.2010.05.023

Imhof HK, Sigl R, Brauer E et al (2017) Spatial and temporal variation of macro-, meso- and microplastic abundance on a remote coral island of the Maldives, Indian Ocean. Mar Pollut Bull 116:340-347. https://doi.org/10.1016/j.marpolbul.2017.01.010

Ivar do Sul JA, Costa MF (2014) The present and future of microplastic pollution in the marine environment. Environ Pollut 185:352-364. https://doi.org/10.1016/j.envpol.2013.10.036

Kelly A, Lannuzel D, Rodemann T et al (2020) Microplastic contamination in east Antarctic sea ice. Mar Pollut Bull 154:111130. https://doi.org/10.1016/j.marpolbul.2020.111130

Khumsaeng T, Kim Oanh NT, Kare KH, Polprasert C (2013) Emission of dioxins/furans and other U-POPs from test burns of nonPOP pesticides in a hazardous waste incinerator. Waste Manage 33:833-841. https://doi.org/10.1016/j.wasman.2012.11.012

Koelmans AA, Bakir A, Allen Burton G, Janssen CR (2016) Microplastic as a vector for chemicals in the aquatic environment: critical review and model-supported reinterpretation of empirical studies. Environ Sci Technol. https://doi.org/10.1021/acs. est. 5 b06069

Kumari K, Sharma JK, Kanade GS et al (2014) Investigation of polybrominated diphenyl ethers in old consumer products in India. Environ Monit Assess 186:3001-3009. https://doi.org/10.1007/ S10661-013-3596-2

Kumari K, Kumar S, Rajagopal V et al (2019) Emission from open burning of municipal solid waste in India. Environ Technol (UK) 40:2201-2214. https://doi.org/10.1080/09593330.2017.1351489

Lebreton L, Andrady A (2019) Future scenarios of global plastic waste generation and disposal. Palgrave Commun 5:1-11. https://doi. org/10.1057/s41599-018-0212-7

Maddela NR, Venkateswarlu K, Kakarla D, Megharaj M (2020) Inevitable human exposure to emissions of polybrominated diphenyl ethers: a perspective on potential health risks. Environ Pollut 266:115240. https://doi.org/10.1016/j.envpol.2020.115240 
Makkar Panwar R, Ahmed S, Sharma A (2018) Bridging the gaps between formal and informal e-waste management in India with EPR. Int J Develop Res 8(1):18501-18506

Mato Y, Isobe T, Takada $\mathrm{H}$ et al (2001) Plastic resin pellets as a transport medium for toxic chemicals in the marine environment. Environ Sci Technol 35:318-324. https://doi.org/10.1021/es0010498

Meeker JD, Sathyanarayana S, Swan SH (2009) Phthalates and other additives in plastics: human exposure and associated health outcomes. Philos Trans R Soc B 364:2097-2113

Meijer LJJ, van Emmerik T, van der Ent R et al (2021) More than 1000 rivers account for $80 \%$ of global riverine plastic emissions into the ocean. Sci Adv 7:eaaz5803. https://doi.org/10.1126/sciadv. aaz5803

Mininni G, Sbrilli A, Braguglia CM et al (2007) Dioxins, furans and polycyclic aromatic hydrocarbons emissions from a hospital and cemetery waste incinerator. Atmos Environ 41:8527-8536. https:// doi.org/10.1016/j.atmosenv.2007.07.015

Mutha NH, Patel M, Premnath V (2006) Plastics materials flow analysis for India. Resour Conserv Recycl 47:222-244. https://doi.org/ 10.1016/j.resconrec.2005.09.003

Nandy B, Sharma G, Garg S et al (2015) Recovery of consumer waste in India: a mass flow analysis for paper, plastic and glass and the contribution of households and the informal sector. Resour Conserv Recycl 101:167-181. https://doi.org/10.1016/j.resconrec. 2015.05.012

Nizzetto L, Sinha S (2020) Top priority to curb plastic pollution: empowering those at the bottom. One Earth 2:11-15. https://doi. org/10.1016/j.oneear.2020.01.005

Oehlmann J, Schulte-Oehlmann U, Kloas W et al (2009) A critical analysis of the biological impacts of plasticizers on wildlife. Philos Trans R Soc B 364:2047-2062

Ogata Y, Takada H, Mizukawa K et al (2009) International pellet watch: global monitoring of persistent organic pollutants (POPs) in coastal waters. 1. Initial phase data on PCBs, DDTs, and HCHs. Mar Pollut Bull 58:1437-1446. https://doi.org/10.1016/j.marpo lbul.2009.06.014

Rajan S, Rex KR, Pasupuleti M et al (2021) Soil concentrations, compositional profiles, sources and bioavailability of polychlorinated dibenzo dioxins/furans, polychlorinated biphenyls and polycyclic aromatic hydrocarbons in open municipal dumpsites of Chennai city, India. Waste Manage 131:331-340. https://doi.org/10.1016/j. wasman.2021.06.015

Ramteke S, Sahu BL (2020) Novel coronavirus disease 2019 (COVID19) pandemic: considerations for the biomedical waste sector in India. Case Stud Chem Environ Eng 2:100029. https://doi.org/10. 1016/j.cscee.2020.100029

Ronnie Rex K, Rajakumaran R, Gaonkar O et al (2019) Recycling processes and plastic in electronic waste is an emerging problem for India: implications for future prospect. Springer, Cham, pp $171-186$

Sakai S, Urano S, Takatsuki H (1998) Leaching behavior of persistent organic pollutants (POPs) in shredder residues. Chemosphere 37:2047-2054

Seltenrich N (2015) New link in the food chain? Marine plastic pollution and seafood safety. Environ Health Perspect 123:A34. https:// doi.org/10.1289/ehp.123-A34

Sepúlveda A, Schluep M, Renaud FG et al (2010) A review of the environmental fate and effects of hazardous substances released from electrical and electronic equipments during recycling: examples from China and India. Environ Impact Assess Rev 30:28-41

Shan G, Wei M, Zhu L et al (2014) Concentration profiles and spatial distribution of perfluoroalkyl substances in an industrial center with condensed fluorochemical facilities. Sci Total Environ 490:351-359. https://doi.org/10.1016/j.scitotenv.2014.05.005

Sharma BM, Bharat GK, Tayal S et al (2014) The legal framework to manage chemical pollution in India and the lesson from the persistent organic pollutants (POPs). Sci Total Environ 490:733747. https://doi.org/10.1016/j.scitotenv.2014.05.043

Shinkuma T, Huong NTM (2009) The flow of E-waste material in the Asian region and a reconsideration of international trade policies on E-waste. Environ Impact Assess Rev 29:25-31. https://doi.org/ 10.1016/j.eiar.2008.04.004

Shukla P, Sharma PK, Pandey S, Chintala V (2021) Unsegregated municipal solid waste in India: current scenario, challenges and way forward. Nat Environ Pollut Technol 20:851-863

Singh P, Singh RP, Srivastava V (2019) Contemporary environmental issues and challenges in era of climate change. In: Singh P et al (eds) Contemporary environmental issues and challenges in era of climate change. Springer, New York, pp 1-293

Someya M, Ohtake M, Kunisue T et al (2010) Persistent organic pollutants in breast milk of mothers residing around an open dumping site in Kolkata, India: specific dioxin-like PCB levels and fish as a potential source. Environ Int 36:27-35

Staines A, Crowley D, Bruen M, O'Connor P (2004) Public health and landfill sites. https://www.academia.edu/27952441/Public_health_ and_landfill_sites. Accessed on 09 Feb 2022

Stockholm Convention (2001) Stockholm convention on persistent organic pollutants. http://www.pops.int/Portals/0/download. aspx $? d=$ UNEP-POPS-COP-CONVTEXT-2021.English.pdf. Accessed 09 Feb 2022

Stockholm Convention (2022) Country profiles. http://chm.pops.int/ Countries/CountryProfiles/tabid/4501/Default.aspx. Accessed on $05 \mathrm{Feb} 2022$

Tan F, Yang H, Xu X et al (2020) Microplastic pollution around remote uninhabited coral reefs of Nansha Islands, South China Sea. Sci Total Environ 725:138383. https://doi.org/10.1016/j.scitotenv. 2020.138383

Tang Z, Huang Q, Cheng J et al (2014) Polybrominated diphenyl ethers in soils, sediments, and human hair in a plastic waste recycling area: a neglected heavily polluted area. Environ Sci Technol 48:1508-1516. https://doi.org/10.1021/es404905u

Teuten EL, Saquing JM, Knappe DRU et al (2009) Transport and release of chemicals from plastics to the environment and to wildlife. Philos Trans R Soc B 364:2027-2045. https://doi.org/ 10.1098/rstb.2008.0284

Thacker N, Sheikh J, Tamane SM et al (2013) Emissions of polychlorinated dibenzo-p-dioxins (PCDDs), dibenzofurans (PCDFs), and dioxin-like polychlorinated biphenyls (PCBs) to air from waste incinerators and high thermal processes in India. Environ Monit Assess 185:425-429. https://doi.org/10.1007/s10661-012-2564-6

Thompson RC, Olsen Y, Mitchell RP et al (2004) Lost at sea: where is all the plastic? Science 304:838. https://doi.org/10.1126/scien ce. 1094559

Toxics Link (2018) Persistent organic pollutants (POPs) in India: country situation report. https://ipen.org/sites/default/files/docum ents/4ind_india_country_situation_report-en.pdf. Accessed on 09-02-2022

UN (United Nations) (2020) Stockholm convention on persistent organic pollutants, India: acceptance of amendment to Annex A, 2020. https://treaties.un.org/doc/Publication/CN/2020/CN.567. 2020-Eng.pdf. Accessed on 05 Feb 2022

Velis CA, Cook E (2021) Mismanagement of plastic waste through open burning with emphasis on the global south: a systematic review of risks to occupational and public health. Environ Sci Technol 55:7186-7207. https://doi.org/10.1021/acs.est.0c08536

Weber R, Watson A, Forter M, Oliaei F (2011) Persistent organic pollutants and landfills: a review of past experiences and future challenges. Waste Manage Res 29:107-121

WEF (2019) A new circular vision for electronics time for a global reboot; Prepared by the World Economic Forum. https://www3. weforum.org/docs/WEF_A_New_Circular_Vision_for_Electronics.pdf. Accessed 09 Feb 2022 
Wiedinmyer C, Yokelson RJ, Gullett BK (2014) Global emissions of trace gases, particulate matter, and hazardous air pollutants from open burning of domestic waste. Environ Sci Technol 48:95239530. https://doi.org/10.1021/es502250z

Zhang K, Su J, Xiong X et al (2016) Microplastic pollution of lakeshore sediments from remote lakes in Tibet plateau, China. Environ Pollut 219:450-455. https://doi.org/10.1016/j.envpol.2016.05.048
Publisher's Note Springer Nature remains neutral with regard to jurisdictional claims in published maps and institutional affiliations. 